\title{
CRESCIMENTO, ACÚMULO DE NUTRIENTE E PROSPECÇÃO FITOQUÍMICA DA JUSTICIA PECTORALIS JACQ EM FUNÇÃO DO TIPO DE ADUBAÇÃO
}

\author{
Rafaela Miguel Vieira ${ }^{1}$, Angélica Siqueira Vieira ${ }^{1}$, Cláudia Fabiana Alves Rezende ${ }^{2}$, Josana de Castro Peixoto ${ }^{3}$
}

\begin{abstract}
RESUMO - O presente estudo propôs verificar o efeito de diferentes tipos de adubação no crescimento vegetal, absorção de nutrientes e presença de metabólitos secundários nas folhas de Justicia pectoralis Jacq cultivadas. Os tratamentos consistiram de três diferentes adubações, orgânica, química e sem adubação, dispostos num delineamento em blocos casualizados, com seis repetições por tratamento. Avaliou-se a biomassa da parte aérea, realizou-se a prospecção fitoquímica e os teores de nutrientes foliares. Houve influência $(\mathrm{P}<0,05)$ das diferentes adubações sobre o crescimento da planta em altura, diâmetro e massa seca, sendo que a adubação química proporcionou maior desenvolvimento da planta. A adubação orgânica disponibiliza maiores concentrações dos elementos N, P, K e Ca. E a mineral maiores teores de Mg. A prospecção fitoquímica realizada apresentou metabólicos como heterosídeos antraquinônicos, taninos e cumarinas. As folhas de $J$. pectoralis apresentaram rendimento de óleos essenciais de $0,05 \%$ sem adubação; $0,03 \%$ em sistema orgânico e $0,09 \%$ em adubação química. Houve influência positiva das diferentes adubações sobre o crescimento da planta. A adubação orgânica disponibilizou maior acúmulo de nutrientes. A prospecção fitoquímica realizada apresentou metabólicos como heterosídeos antraquinônicos, taninos e cumarinas, sendo que o rendimento de óleos essenciais foi maior nas plantas com adubação orgânica.
\end{abstract}

Palavras chave: chambá, metabólitos secundários, plantas medicinais.

\section{GROWTH, NUTRIENT ACCUMULATION AND PHYTOCHEMICAL PROSPECTION OF JUSTICIA PECTORALIS JACQ AS A FUNCTION OF FERTILIZATION TYPE}

\begin{abstract}
The present study proposed to verify the effect of different types of fertilization on plant growth, nutrient uptake and presence of secondary metabolites in leaves of Justicia pectoralis Jacq cultivated. The treatments consisted of three different fertilizers, organic, chemical and without fertilization, arranged in a randomized block design with six replications per treatment. Shoot biomass was evaluated, phytochemical prospecting and leaf nutrient contents were performed. There was influence $(P<0.05)$ of different fertilizers on plant growth in height, diameter and dry mass, and chemical fertilization provided greater plant development. Organic fertilization provides higher concentrations of $N, P, K$ and Ca elements. And the mineral higher Mg contents. The phytochemical prospecting performed showed metabolic as anthraquinonic heterosides, tannins and coumarins. The leaves of J. pectoralis presented essential oils yield of $0.05 \%$ without fertilization; $0.03 \%$ in organic system and $0.09 \%$ in chemical fertilization. There was a positive influence of different fertilizers on plant growth. Organic fertilization provided greater nutrient accumulation. The phytochemical prospecting performed showed metabolic as anthraquinonic heterosides, tannins and coumarins, and the yield of essential oils was higher in plants with organic fertilization. The phytochemical prospecting performed showed metabolic as anthraquinonic heterosides, tannins and coumarins, and the yield of essential oils was higher in plants with organic fertilization.
\end{abstract}

Keywords: medicinal plants, secondary metabolites, tilo.

Bolsista de iniciação científica, graduanda em Agronomia da UniEvangélica, Anápolis, GO.

2 Doutora em Agronomia, professora do curso de Agronomia, UniEvangélica, Anápolis, GO. E-mail: claudia7br@msn.com.

3 Doutora em Biologia, professora do PPSTMA da UniEvangélica e docente da Universidade Estadual de Goiás.

E-mail: josana.peixoto@gmail.com. 


\section{INTRODUÇÃO}

As plantas medicinais têm sido usadas para o tratamento de diversas doenças decorrentes de conteúdos ativos fitoquímicos (Chanfrau \& Rodríguez, 2014). Justicia pectoralis, conhecida como chambá e/ou anador, é efetiva no tratamento de hipertensão arterial (García-Lazo et al., 2015) apresenta efeitos anti-inflamatórios, estrogênicos e progestagênicos (Locklear et al., 2010) e efeito ansiolítico (Venâncio et al., 2014).

A espécie $J$. pectoralis encontra-se na Relação Nacional de Plantas Medicinais de Interesse (Brasil, 2018), sendo importante sua pesquisa como potencial na produção de fitoterápicos. Segundo Costa et al. (2008), cerca de $90 \%$ de toda droga vegetal brasileira ainda é obtida por extrativismo, o que leva a pesquisas agronômicas conduzidas com o intuito de investigar a influência da adubação química e orgânica sobre a biomassa e o rendimento de metabólitos secundários de diferentes espécies medicinais.

Ainda são muito escassas as informações disponíveis sobre o comportamento das plantas medicinais, aromáticas e condimentares quando estas são submetidas às técnicas de produção agrícola (Pravuschi et al., 2010). Vários resultados destacam que a produção tanto de biomassa quanto de metabólitos secundários varia em função da espécie e dos adubos utilizados como os estudos com Justicia pectoralis de Bezerra et al. (2006), Andrade et al. (2012), Chanfrau \& Ferrada (2014) e Ferreira et al. (2015), que destacam a importância da produção das plantas medicinais.

Diante do contexto e considerando a importância de novos estudos sobre plantas com potencial medicinal, o presente estudo propôs verificar o efeito de diferentes tipos de adubação no crescimento vegetal, absorção de nutrientes e presença de metabólitos secundários nas folhas de Justicia pectoralis Jacq (Acanthaceae) cultivadas em Anápolis, Estado de Goiás, Brasil.

\section{MATERIAL E MÉTODOS}

O estudo foi desenvolvido no município de Anápolis, Goiás, Brasil, nas coordenadas geográficas, Latitude $16^{\circ} 19^{\prime \prime} 36^{\prime} \mathrm{S}$ e Longitude $48^{\circ} 27^{\prime}$ ' $10^{\prime} \mathrm{W}$, com altitude $1.030 \mathrm{~m}$. O clima da região é classificado de acordo com Köppen, como Aw (tropical com estação seca), com mínima de $18{ }^{\circ} \mathrm{C}$ e máxima de $32{ }^{\circ} \mathrm{C}$, média $22{ }^{\circ} \mathrm{C}$, com chuvas de outubro a abril e precipitação pluviométrica média anual de $1.450 \mathrm{~mm}$. O solo foi classificado como
Latossolo Vermelho eutófico típico (Santos et al., 2013), com $33 \%$ argila, $19 \%$ silte e $48 \%$ areia, textura média.

Foi realizada na área, antes da implantação, uma amostragem de solo $(0-0,20 \mathrm{~m})$ com trado holandês e analisada conforme metodologia da Embrapa (2011). Os resultados obtidos na análise química do solo demonstraram saturação de bases (V) 52,9\%, $\mathrm{pH} \mathrm{CaCl}_{2} 5,1, \mathrm{Ca} 2,70 \mathrm{cmol}_{\mathrm{c}}$

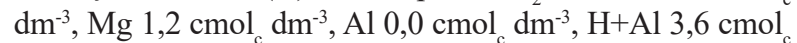
$\mathrm{dm}^{-3}$, CTC 7,60 $\mathrm{cmol}_{\mathrm{c}} \mathrm{dm}^{-3}, \mathrm{~K} 54 \mathrm{mg} \mathrm{dm}^{-3}, \mathrm{P}$ (Mel) 1,6 mg $\mathrm{dm}^{-3}$, MO 2,70\%.

As plantas de $J$. pectoralis foram propagadas pelo método de estaquia. Para tanto, as estacas foram coletadas de plantas matrizes vigorosas e sadias no horto medicinal da Unidade Experimental. Posteriormente foram seccionadas em $12 \mathrm{~cm}$ e com cinco gemas viáveis. $\mathrm{O}$ plantio foi realizado em sacos de polietileno de $10 \mathrm{~cm}$ x 15 $\mathrm{cm}$, preenchidos com substrato comercial.

As estacas foram plantadas com duas gemas enterradas, e mantidas em ambiente $50 \%$ sombreado até o transplantio. O suprimento d'água para as mudas foi efetuado mediante irrigações diárias, com auxílio de regador. Trinta dias após o plantio, as mudas foram transplantadas para os canteiros. Foi utilizado o espaçamento de 0,25 m x 0,30 m, com dimensão da parcela de $1,30 \mathrm{~m}$ x 2,30 m, seguindo a metodologia proposta por Bezerra et al. (2006).

Os tratamentos consistiram de adubação orgânica (esterco de aves), química e a testemunha (sem adubação), dispostos num delineamento em blocos casualizados, com seis repetições. Os resultados obtidos na análise química do adubo orgânico demonstraram $\mathrm{V} \mathrm{89,7 \% ,} \mathrm{pH} \mathrm{CaCl}_{2} 7,0, \mathrm{Ca}$

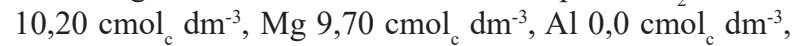
$\mathrm{H}+\mathrm{Al} 2,60 \mathrm{cmol}_{\mathrm{c}} \mathrm{dm}^{-3}$, CTC $25,3 \mathrm{cmol}_{\mathrm{c}} \mathrm{dm}^{-3}, \mathrm{~K} 1.105,0 \mathrm{mg}$ $\mathrm{dm}^{-3}$, P (Mel) 857,1 $\mathrm{mg} \mathrm{dm}^{-3}$, MO 7,20\%.

Antes do transplantio foi incorporado calcário na área $\left(2 \mathrm{t} \mathrm{ha}^{-1}\right)$. No tratamento orgânico foi adicionado no plantio $75 \mathrm{~g} \mathrm{cova}^{-1}$, no químico foram incorporados adubo equivalente $\mathrm{N}-\mathrm{P}_{2} \mathrm{O}_{5}-\mathrm{K}_{2} \mathrm{O}$ em kg ha- ${ }^{-1}, 50-100-40$. O controle das plantas daninhas foi realizado através de capinas manuais.

Aos 30, 90 e 120 dias após o transplante foram determinadas em dez plantas da área útil de cada parcela, a altura e diâmetro. Na última avaliação as plantas foram colhidas manualmente. A parte aérea das plantas foram lavadas em água corrente e submetidas à secagem em estufa com circulação forçada de ar a $60{ }^{\circ} \mathrm{C}$, durante $72 \mathrm{~h}$, para determinação da massa seca. Avaliou-se a biomassa da parte aérea $(\mathrm{g})$, teores de nutrientes foliares e a prospecção fitoquímica. 
Para os teores de nutrienes, as amostras foram lavadas em água corrente e colocadas em sacos de papel para secagem em estufa. Os teores de nutrientes foliares foram estimados de acordo com as seguintes metodologias: nitrogênio (N) (método micro Kjeldahl), fósforo total (P) (colorimetra - método de metavanadato), potássio (fotometria de chama), enxofre total (S) (método turbidimétrico), cálcio $(\mathrm{Ca})$, magnésio $(\mathrm{Mg})$, cobre $(\mathrm{Cu})$, ferro $(\mathrm{Fe})$, manganês $(\mathrm{Mn})$ e zinco $(\mathrm{Zn})$ (método espectrofotometria de absorção atômica) (Embrapa, 2011).

Na prospecção fitoquímica, as análises qualitativas das principais classes de metabólitos secundários presentes nas folhas foram realizadas segundo metodologia adaptada de Faria (2008) e Souza (2005). O teor de umidade de drogas vegetais é um parâmetro que pode interferir consideravelmente na estabilidade dos componentes ativos (Fonseca et al., 2010). Por esta razão o teor de umidade estabelecido em várias farmacopeias, incluindo a do Brasil, é de $8-14 \%$.

A determinação de cinzas insolúveis em ácido visa avaliar separadamente a presença de cinzas que não são de origem fisiológica, como resíduos silicosos. Os insumos de origem natural normalmente apresentam teores inferiores a 1\% para cinzas insolúveis em ácido (Simões et al., 2017).

Para extração do óleo essencial, $8,8 \mathrm{~g}$ de material botânico foram utilizadas e, posteriormente submetidas à hidrodestilação em aparelho do tipo Clevenger modificado, durante $2 \mathrm{~h}$. O volume do óleo essencial foi medido no tubo graduado do próprio aparelho e o rendimento, em porcentagem, foi calculado em relação à quantidade inicial de material botânico empregado nas extrações. Os óleos essenciais assim obtidos foram dessecados com $\mathrm{Na}_{2} \mathrm{SO}_{4}$ anidro, acondicionados em recipientes livres de impurezas, hermeticamente fechados e estocados a baixas temperaturas até a sua utilização.

Os dados obtidos foram comparados através da análise de variância, utilizando o teste $\mathrm{F}$; as médias foram comparadas pelo teste de Tukey $(\mathrm{P}<0,05)$, o programa estatístico utilizado foi o Sisvar (Ferreira, 2011),

\section{RESULTADO E DISCUSSÃO}

Estatisticamente se observa que os valores de altura não diferiram entre si dentro dos dias observados nos diferentes tratamentos e ocorre diferenças no diâmetro dentro dos dias na segunda e terceira avaliação (Figura 1). $\mathrm{O}$ diâmetro do caule, que está relacionado à capacidade de transporte de nutrientes pela planta, apresenta aumento de $4,31 \mathrm{~mm}$ a cada 30 dias na presença da adubação química atingindo $17,47 \mathrm{~mm}$ aos 120 dias, demostrando que a planta por ser suberecta prioriza o crescimento em diâmetro do caule. As plantas adubadas com adubo químico apresentaram maior altura e diâmetro (Figura 1).
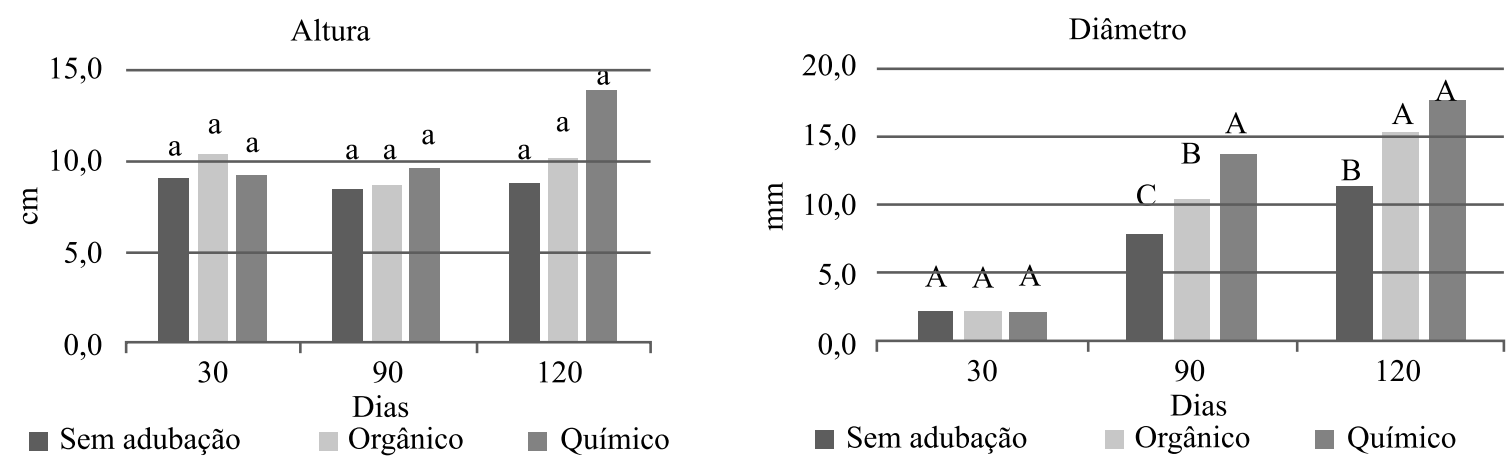

Letras iguais, no topo das colunas indicam que as médias dentro de cada avaliação (dias) não diferem entre si pelo teste de Tukey ( $(\mathrm{P}<0,05)$.

Figura 1 - Altura e diâmetro, nos dias após o transplantio, de plantas de Justicia pectoralis em função dos diferentes tipos de adubação em Latossolo Vermelho, Anápolis, GO, Brasil, 2018.

Um dos fatores mais importantes na produtividade de plantas medicinais é a sua produção de massa seca (Costa et al., 2008). Os diferentes tipos de adubação das plantas de $J$. pectoralis resultou em diferentes acúmulos de massa seca, sendo que as plantas adubadas com adubo químico apresentaram maior produção de massa seca (Tabela 1).

Com relação ao acúmulo de massa seca, Silva et al. (2003) constatou maior acúmulo com o uso de adubo 
organomineral no capim-limão, Bezerra et al. (2006) observou em $J$. pectoralis as doses de adubações orgânicas e minerais não influenciaram a produção de biomassa da planta e Costa et al. (2008) observou que a adubação com esterco de aves promoveu o maior acúmulo em capim-limão. Este diferente comportamento evidência que diferentes tipos de adubação, podem apresentar resultados satisfatórios com a produção de massa seca de plantas medicinais.

Os resultados da diagnose foliar evidenciam efeitos significativos entre os diferentes tipos de adubação e os teores de nutrientes na massa seca das plantas de $J$. pectoralis. Apresentaram diferenças significativas $(\mathrm{P}<0,05)$ para os elementos N, P, K, Ca, Mg (Tabela 1). O Ca e K foram os nutrientes que apresentaram maior concentração.

Franco et al. (2011) destacam que se pode manipular o tipo de fertilizante usado, para favorecer a absorção de certos nutrientes nas plantas medicinais. As maiores concentrações de nutrientes foram observadas no tratamento sem adubação, seguido pela adubação orgânica, este fator pode estar relacionado ao efeito diluição.

Tabela 1 - Concentração de nutrientes em folhas de Justicia pectoralis e matéria seca aos 120 DAE (dias após a emergência) em função duos diferentes tipos de adubação em Latossolo Vermelho, Anápolis, GO, Brasil, 2018

\begin{tabular}{|c|c|c|c|c|c|c|c|c|c|c|c|c|}
\hline \multirow{3}{*}{$\begin{array}{c}\text { Adubações } \\
\text { Sem adubação }\end{array}$} & \multicolumn{10}{|c|}{ g $100 \mathrm{~g}^{-1}$} & \multirow{2}{*}{\multicolumn{2}{|c|}{$\frac{\text { Massa seca }(\mathrm{g})}{120 \text { dias }}$}} \\
\hline & \multirow{2}{*}{$\frac{\mathrm{N}}{2,080}$} & & \multirow{2}{*}{$\frac{P}{0,143}$} & \multicolumn{3}{|c|}{$\mathrm{K}$} & \multirow{2}{*}{$\frac{\mathrm{Ca}}{4,008}$} & \multicolumn{3}{|c|}{$\mathrm{Mg}$} & & \\
\hline & & $\mathrm{a}$ & & $\mathrm{b}$ & 2,738 & $\mathrm{a}$ & & $\mathrm{a}$ & 1,018 & $\mathrm{a}$ & 6,26 & $\mathrm{~b}$ \\
\hline Orgânico & 2,156 & $\mathrm{a}$ & 0,198 & $\mathrm{a}$ & 2,708 & $\mathrm{a}$ & 3,765 & $a b$ & 0,953 & $\mathrm{~b}$ & 10,55 & $\mathrm{a}$ \\
\hline Químico & 1,943 & b & 0,150 & $\mathrm{~b}$ & 2,331 & $\mathrm{~b}$ & 3,505 & $\mathrm{~b}$ & 0,995 & $a b$ & 11,49 & $\mathrm{a}$ \\
\hline Teste F & 0,00 & $* *$ & 0,00 & $* *$ & 0,00 & $* *$ & 0,01 & $* *$ & 0,05 & * & 0,00 & $* *$ \\
\hline CV (\%) & 7,18 & & 18,43 & & 7,6 & & 12,17 & & 8,08 & & 32,47 & \\
\hline
\end{tabular}

Letras iguais na coluna, indicam que as médias dentro de cada avaliação não diferem entre si pelo teste de Tukey a $5 \%$ de probabilidade.

A concentração de $\mathrm{N}$ variou de $1,943 \mathrm{~g}$ a 2,156 g $100 \mathrm{~g}^{-1}$, na adubação química e orgânica respectivamente. As plantas sem adubação estavam visivelmente amareladas em relação às demais. Estas respostas estão ligadas diretamente ao aumento da disponibilidade nutricional, especialmente de $\mathrm{N}$ e $\mathrm{Mg}$, principais constituintes do anel porfirínico na molécula de clorofila. Segundo Santos et al. (2001), parte dos nutrientes presentes em fertilizantes orgânicos resiste à rápida mineralização, e se estarão disponíveis para as culturas subsequentes.

O teor de P na matéria seca da planta foi maior na

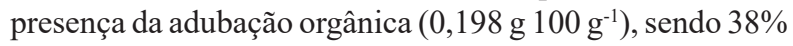
e $32 \%$ maior que o observado nas plantas não adubadas e com adubação química, respectivamente. Como a análise química inicial do solo demostrou níveis muito baixos de $\mathrm{P}$, pode se inferir que a adição da adubação orgânica favoreceu formas de P lábil no solo e maior absorção pelas plantas. Bezerra et al. (2006) observou valores entre 0,03 g a 0,07 g $100 \mathrm{~g}^{-1}$, valores inferiores ao observado neste trabalho. Sendo que os autores destacam que não ocorre incremento nos teores de $\mathrm{P}$ com o uso de adubação orgânica e química na massa seca da parte aérea de $J$. pectoralis.

Os valores de $\mathrm{K}$ variam entre 2,331 g a 2,738 g $100 \mathrm{~g}^{-1}$ (tabela 1), sendo que Almeida et al. (2002) trabalhando com Justicia gendarussai L., obteve concentrações de K de 4,0 g $100 \mathrm{~g}^{-1}$, enquanto que Bezerra et al. (2006) com

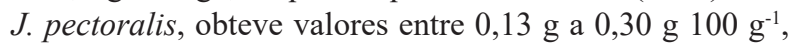
influenciados pela adubação, o que corrobora o observado neste trabalho.

O uso da adubação orgânica aumenta a concentração de $\mathrm{K}$ na matéria seca, como o observado no trabalho de Chaves (2002) com alfavaca-cravo; Bezerra (2003) com macela e Bezerra et al. (2006) com J. pectoralis.

Os teores de $\mathrm{Ca}$ nas plantas podem variar de

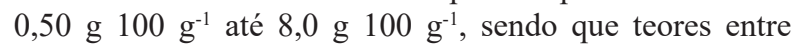

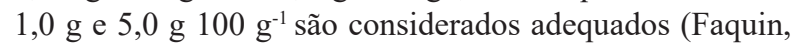
2005). Os teores de $\mathrm{Ca}$ se aprestaram dentro da faixa considerada adequada. Almeida et al. (2002) trabalhando com Justicia gendarussai L., obtiveram concentrações de Ca de 0,941 g a 0,959 g $100 \mathrm{~g}^{-1}$, sendo esses valores superiores ao observado (Tabela 1). Os autores destacam a grande demanda de $\mathrm{Ca}$ e $\mathrm{Mg}$ pelas plantas de Justicia sp., o que também foi observado, sendo o Ca o nutriente mais concentrado na matéria seca das plantas de J. pectoralis. Observa-se relação $\mathrm{Ca}: \mathrm{Mg}$ de 4:1 na adubação orgânica e 3,5:1 para a adubação química, sendo que Almeida et al. (2002) observaram relação de 6:1 em J. gendarussai, mostrando um acúmulo de Ca no tecido foliar da planta. 
A concentração de $\mathrm{Mg}$ no tecido vegetal variou de $0,953 \mathrm{~g}$ a $1,018 \mathrm{~g} 100 \mathrm{~g}^{-1}$. Almeida et al. (2002) observaram

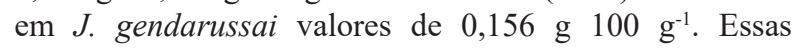
variações encontradas nos teores de nutrientes podem ser explicadas, segundo Gobbo-Neto \& Lopes (2015), pela influência de fatores externos e internos e suas relações, atuando e interferindo na absorção iônica. Baixos teores de $\mathrm{Mg}$ no solo induzem ao menor aproveitamento do $\mathrm{P}$ disponibilizado.

À medida que se aumenta essa relação ocorre a maior disponibilidade de $\mathrm{Ca}$ em relação ao $\mathrm{Mg}$ na solução do solo, favorecendo a sua absorção. $\mathrm{O}$ acúmulo preferencial de $\mathrm{Ca}$ pelas plantas se dá, provavelmente, porque a ocorra maior disponibilidade de Ca no solo, o que promove sua aproximação às raízes em maior quantidade (Medeiros et al., 2008).

Segundo Gobbo-Neto \& Lopes (2007), a adição de nutrientes via adubação afeta a produção de diferentes metabólitos secundários com impacto e mudanças em sua disponibilidade na produção. De acordo com os autores estes efeitos não são totalmente previsíveis; tendências podem ser reconhecidas, mas não é possível estabelecer regras sólidas e estáveis.

No presente trabalho a secagem da planta em estufa resultou em um teor de umidade $8,76 \% \pm 0,18$ e desvio padrão relativo $2,0 \%$, dentro dos limites recomendados (Brasil, 2010). Estudos anteriores de Vagem (2015) confirmam o valor encontrado para cinzas não fisiológicas da espécie. Os teores médios de cinzas totais e cinzas insolúveis em ácido clorídrico encontrados para as folhas de J. pectoralis foram: $12,27 \%$ e $1,21 \%$ sem adubação, $13,05 \%$ e 1,30\% com uso da adubação orgânica e 12,78\% e $1,62 \%$ com uso da adubação química, demostrando que a adubação orgânica foi mais eficiente no acúmulo de cinzas torais e a adubação química maior concentração de cinzas insolúveis.

Os resultados dos testes fitoquímicos para a detecção das principais classes de metabólitos secundários presentes no pó das folhas de $J$. pectoralis constataram a presença de heterosídeos antraquinônicos, taninos e cumarinas, nas folhas adultas, o que corrobora o observado por Silva \& Peixoto (2013), que também observaram a presença de heterosídeos antraquinônicos e cardioativos, taninos, cumarinas e flavonoides em Justicia thunbergioides e Araújo et al. (2014) que observaram a presença alcalóides, flavonóides, esteróides, saponinas e cumarinas em $J$. pectoralis.

A presença de cumarinas é apontada como caraterístico à espécie $J$. pectoralis sendo comumente relatados em ensaios de prospecção fitoquímica, cromatografia em camada delgada e cromatografia a líquido de alta eficiência (Vargem, 2015; Oliveira et al., 2000). No presente estudo foi evidenciada a presença desta classe de metabólitos secundários. Vagem (2015) relatou a presença de saponinas nas folhas de $J$. pectoralis. Este grupo de metabólitos não pôde ser observado no presente trabalho, assim como não foi observado em estudo de Oliveira et al. (2000).

A identificação de núcleo esteroide e desoxiaçúcares, caracterizada nas reações de LiebermannBurchad, Pesez e Keller-Kiliani, não permitem afirmar a presença de heterosídeos cardioativos. Não foi verificado a presença de alcaloides, indicando que o uso de $J$. pectoralis em preparações ritualísticas deve-se apenas ao seu efeito aromatizante causado pela presença intensa das cumarinas (Oliveira et al., 2000; Vargem, 2015).

Segundo Carmo et al. (2011), a adubação orgânica está diretamente relacionada a produção dos metabolitos secundários. As plantas estudadas apresentaram teores considerados adequados de macronutrientes nas folhas, em todos diferentes tipos de adubação empregadas foram detectados os metabólitos secundários.

As folhas de $J$. pectoralis apresentaram rendimento de óleos essenciais de $0,05 \%$ sem adubação; $0,03 \%$ orgânico e $0,09 \%$; adubação química. Segundo Joseph et al. (1988), em estudos sobre a composição química de óleos essenciais, o rendimento encontrado para a espécie $J$. pectoralis coletada Guadeloupe, na Índia, o rendimento variou entre $0,4 \%$ a $0,3 \%$. Neste sentido, são razoáveis os rendimentos encontrados para as diferentes espécies de Justicia sp. A variabilidade na produção e teor de óleos essenciais é conhecida por ser afetada por fatores ambientais tais como luz, disponibilidade de nutrientes, estação do ano, período do dia, ciclo e parte da planta

Castro (2002) em estudo sobre preparados de fitoterápicos, dentre eles da planta J. pectoralis, encontrouse rendimento de $2,9 \%$. Portanto, os espécimes avaliados neste trabalho possuem um rendimento de óleo essencial abaixo do relatado na literatura citada. Este fato pode ser atribuído a época do ano em que foi feita a coleta, estádio de desenvolvimento do vegetal, localidade geográfica (altitude), e fatores ambientais como luz, disponibilidade de nutrientes, estação do ano, período do dia.

Apesar do extrato de $J$. pectoralis já ser utilizado na forma de xarope fitoterápico, poucos são os métodos encontrados na literatura para a análise quantitativa de cumarinas nesse extrato. No entanto, o controle de qualidade de insumos fitoterápicos da espécie é baseado no 
teor de cumarinas, sendo a quantificação destes metabólitos secundários, um importante parâmetro que pode inferir na qualidade da matéria-prima vegetal, bem como na eficiência do método de extração empregado (Nolla \& Severo, 2005).

\section{CONCLUSÃO}

Houve influência positiva das diferentes adubações sobre o crescimento da planta. A adubação orgânica disponibilizou maiores acúmulos do N, P, K e Ca e a adubação mineral maior acúmulo do $\mathrm{Mg}$.

A prospecção fitoquímica realizada apresentou metabólicos como heterosídeos antraquinônicos, taninos e cumarinas, sendo que o rendimento de óleos essenciais foi maior nas plantas com adubação orgânica.

\section{AGRADECIMENTOS}

Ao Centro Universitário de Anápolis UniEvangélica, pela bolsa de Iniciação Científica (PIBIC) concedida, bem como ao suporte técnico, laboratorial e teórico disponibilizado pela instituição.

\section{LITERATURA CITADA}

ALMEIDA, M. M. B.; LOPES, M. D. F. G.; NOGUEIRA, C. M. D. et al. Determinação de nutrientes minerais em plantas medicinais. Ciência e Tecnologia de Alimentos, v. 22, n. 1, p. 94-97, 2002.

ANDRADE, F. M. C.; CASALI, V. W. D.; CECON, P. R. C. Crescimento e produção de cumarina em plantas de chambá (justicia pectoralis jacq.) tratadas com isoterápico. Revista Brasileira de Plantas Medicinais, v. 14, p. 154-158, 2012.

ARAÚJO, L. L. N.; FARIA, M. J. M.; SAFADI, G. M. V. V. Prospecção fitoquímica da espécie Justicia pectoralis Jacq. var. stenophylla Leonard pertencente à família Acanthaceae. Revista Eletrônica de Ciências Humanas, Saúde e Tecnologia, v. 6, n. 2, p. 4-14, 2014.

BRASIL. Agência Nacional de Vigilância Sanitária. Farmacopeia Brasileira, 5.ed., v.1, p.192. Brasília, DF, Anvisa, 2010.

BRASIL, Ministério da Saúde. Plantas de Interesse ao SUS. Portal da saúde [online]. Acesso em: 2018 Mar 22. Disponível em:

http://portalms.saude.gov.br/acoes-e-programas/programanacional-de-plantas-medicinais-e-fitoterapicos-ppnpmf/ politica-e-programa-nacional-de-plantas-medicinaise-fitoterapicos/plantas-medicinais-de-interesse-ao-susrenisus

BEZERRA, A. M. E. Desenvolvimento de um sistema de produção para macela (Egletes viscosa (L.) Less). $125 \mathrm{f}$. 2003. Tese de Doutorado. Tese (Doutorado em Fitotecnia), Universidade Federal do Ceará, Fortaleza.

BEZERRA, A. M.; NASCIMENTO JÚNIOR, T.; LEAL, F. R. et al. Yielding of biomass, essential oil, contents phosphorus and potassium of Justicia pectoralis var. stenophylla in response to the fertilization organic and mineral. Revista Ciência Agronômica, v. 37, n. 2, p. 124, 2006.

CARMO, D. D. R. M.; FORMAGIOII, V. A. S. N.; DOFFINGER, C. A. L. C. D. et al. Atividade antioxidante de Hibiscus sabdariffa L. em função do espaçamento entre plantas e da adubação orgânica. Ciência rural, v. 41, n. 8, p. 1331-1336, 2011.

CASTRO, D. M. Preparações homeopáticas em plantas de cenoura, beterraba, capim-limão e chambá. 2002. $227 \mathrm{f}$. Tese (Doutorado em Fitotecnia) - Universidade Federal de Viçosa, Viçosa. 2002.

CHANFrAU, R. J. E.; RODRÍGUEZ, C. Harvest time influences on coumarin and umbelliferone contents in extracts of Justicia pectoralis Jacq. (tilo). Revista Cubana de Farmácia, v.48, p.477-485; 2014.

CHANFRAU, C. J. E. R.; FERRADA, C. R. Harvest time influences on coumarinand umbelliferone. Revista Cubana de Farmacia, v. 48, n. 2, p. 477-485, 2014.

CHAVES, F.C. M. Produção de biomassa, rendimento e composição de óleo essencial de alfavaca-cravo (Ocimum gratissimum L.) em função da adubação orgânica e épocas de colheita. Botucatu: UNESP. 144p (Tese doutorado). 2002.

COSTA, L. C. B.; ROSAL, L. F.; PINTO, J. E. B. P. et al. Efeito da adubação química e orgânica na produção de biomassa e óleo essencial em capim-limão [Cymbopogon citratus (DC.) Stapf.]. Revista Brasileira de Plantas Medicinais, v. 10, n. 1, p. 16-20, 2008.

EMBRAPA - EMPRESA BRASILEIRA DE PESQUISA AGROPECUÁRIA. Centro Nacional de Pesquisas de Solos. Manual de métodos de análises de solos. 2.ed. Rio de Janeiro: Embrapa Solos, 2011. 230p.

FAQUIN, V. Nutrição Mineral de Plantas/Valdemar Faquin. Lavras: UFLA/FAEPE. Pós-Graduação "Lato Sensu" (Especialização) a Distância: Solos e Meio Ambiente, 2005. 
FARIA, M. T. Morfologia, Anatomia, Histoquímica e Fitoquímica de espécies do gênero Hypenia (Mart. ex Benth.) R. Harley-Lamiaceae ocorrentes no Cerrado de Goiás. 2008. 207p. Dissertação (Mestrado em biologia) - Universidade Federal de Goiás, Instituto de Ciências Biológicas. Goiânia, 2008.

FERREIRA, D.F. Sisvar: a computer statistical analysis system. Ciência e Agrotecnologia, v. 35, n. 6, p. 1039-1042, 2011.

FERREIRA, T. A.; CHAVES, P. P. N.; GELLEN, L. F. A. et al. Produção de mudas de chambá (Justicia pectoralis Jacq) em diferentes tipos de substratos e tamanhos de recipientes. Agropecuária Científica no Semiárido, v. 11, p. 93-96, 2015.

FRANCO, M. J.; DA SILVA CAETANO, I. C.; CAETANO, J. et al. Determinação de metais em plantas medicinais comercializadas na região de Umuarama-PR. Arquivos de Ciências da Saúde da UNIPAR, v. 15, n. 2, 2011.

FONSECA F. N.; SILVA A. H., LEAL L. K. A. M. Justicia pectoralis Jacq. Acanthaceae: preparation and characterisation of the plant drug including chromatographic analysis by HPLC-PDA. Revista Brasileira de Farmacognosia, v. 20, p. 871-877, 2010.

GARCÍA-LAZO, G.; LAUZANT-DIAZ, E.; BATISTA, A. D.; GARCIA-MESA, M. Plants considered useful for hypoglycemic, antihypertensive or hypolipidemic treatments by patients with peripheral vascular diseases. Revista Cubana de Plantas Medicinales, v. 20, n.1, 2015.

GOBBO-NETO, L.; LOPES, N. P. Plantas medicinais: fatores de influência no conteúdo de metabólitos secundários. Química nova, v. 30, n. 2, p. 374, 2007.

JOSEPH, H.; GLEYE, J.; MOULIS, C. et al. Justicidin B, a cytotoxic principle from Justicia pectoralis. Journal of Natural Products, v. 51, n. 3, p. 599-600, 1988.

LOCKLEAR, T. D.; HUANG, Y.; FRASOR, J. et al. Estrogenic and progestagenic effects of extracts of Justicia pectoralis Jacq., an herbal medicine from Costa Rica used for the treatment of menopause and PMS. Maturitas, v. 66, n. 3, p. 315-322, 2010.

MEDEIROS, J. C.; ALBUQUERQUE, J. A.; MAFRA, Á. L. et al. Relação cálcio: magnésio do corretivo da acidez do solo na nutrição e no desenvolvimento inicial de plantas de milho em um Cambissolo Húmico Álico. Semina: Ciências Agrárias, v. 29, n. 4, 2008.
NOLLA, D.; SEVERO, B. M. A. Plantas medicinais. 2a Edição, Passo Fundo: Editora Universitária UPF, v. 72, 2005.

OLIVEIRA A. F. M.; ANDRADE L. H. C. Caracterização morfológica de Justicia pectoralis Jacq. E J. gendarussa Burm. F. (Acanthaceae). Revista Acta Amazônica, v. 30, p. 569-578, 2000.

PRAVUSCHI, P. R.; MARQUES, P. A. A.; RIGOLIN, B. H. M.; SANTOS, A. C. P. Efeito de diferentes lâminas de irrigação na produção de óleo essencial do manjericão (Ocimum basilicum L.). Acta Scientiarum Agronomy, v. 32, n. 4, p. 687-693, 2010.

SANTOS, R.H.S.; SILVA, F.; CASALI, V.W.D. et al. Efeito residual da adubação com composto orgânico sobre o crescimento e produção de alface. Pesquisa Agropecuária Brasileira, v. 36, n. 11, p. 1395-1398, 2001.

SANTOS, H. G.; JACOMINE, P. K. T.; DOS ANJOS, L. H. C. et al. Sistema brasileiro de classificação de solos. Brasília, DF: Embrapa, 2013.

SILVA, P.A.; BLANK, A.F.; ARRIGONI-BLANK, M.D.F. et al. Efeitos da adubação orgânica e mineral na produção de biomassa e óleo essencial do capim limão [Cymbopogon citratus (D.C.) Stapf]. Revista Ciência Agronômica, v. 34, n. 1, p. 5-9, 2003.

SILVA, R. S. G.; PEIXOTO, J. C. Acanthaceaes do Bioma Cerrado: Identificação dos fitoquímicos das folhas da espécie Justicia thunbergioides (Lindau) Leonard (Acanthaceae) ocorrente no parque estadual Serra dos Pireneus, Pirenópolis, GO. Fronteiras: Journal of Social, Technological and Environmental Science, v. 2, n. 1, p. 16-27, 2013.

SIMÕES, C.M.O.; SCHENKEL E.P.; MELLO J.C.P. et al. Farmacognosia: do produto natural ao medicamento. Porto Alegre: Artmed, 2017.

SOUZA, V. C.; LORENZI, H. Botânica sistemática. Nova Odessa, SP: Instituto Plantarum, 2005.

VARGEM, D. S. Morfoanatomia, prospecção fitoquímica e caracterização do óleo essencial das folhas de Justicia pectoralis Jacq. (ACANTHACEAE) ocorrente em Brasilia, $D F$. Dissertação de Mestrado em Ciências Ambientais, Unievangélica, GO, 2015.

VENÂNCIO, E. T.; FEITOSA, M. L.; LINHARES, M. I. et al. Anticonvulsant and antioxidant effects of chamba (Justicia pectoralis) in mice: Involvement of GABA receptor. Epilepsy \& Behavior, v. 38, p. 218, 2014.

Recebido para publicação em 01/07/2019 e aprovado em 02/12/2019. 